\title{
PENGARUH CORE QUALIT, RELATIONAL QUALITY, PERCEIVED VALUE, CUSTOMER SATISFACTION, SERVICE SWITCHING DAN VOICE TERHADAP LOYALITY PADA KANTOR KONSULTAN PAJAK HUSNI \& MULYADI CONSULTING
}

\author{
Sunandar ${ }^{1}$, Hesti Widianti ${ }^{2}$, Erni Unggul Sedya Utami ${ }^{3}$ \\ Email : nandars2ak@gmail.com \\ DIII Akuntansi Politeknik Harapan Bersama Tegal
}

\begin{abstract}
This study aimed to determine whether the core quality, relational quality, perceived value, customer satisfaction service, switching and voice significant effect partially and simultaneously to loyality to the Office of Tax Consultants Husni \& Mulyadi Consulting and to determine which variables most influence on loyalty in Husni \& Mulyadi Tax Consulting among core quality, relational quality, perceived value, customer satisfaction, service switching and voice. Some of the benefits expected from the results of this research that the researchers expected to improve the knowledge of scientific thinking and the ability to analyze a problem, especially with regard to core quality, relational quality, perceived value, customer satisfaction service, switching and voice effect on loyalty.

The results of the regression test core quality, relational quality, perceived value, and customer satisfaction was significantly partially loyality to the Office of Tax Consultants Husni \& Mulyadi Consulting. While the service switching and voice no significant effect partially on loyality to the Office of Tax Consultants Husni \& Mulyadi Consulting. Core quality variable, relational quality, perceived value, customer satisfaction, service switching, and voice simultaneously significant effect on loyalty to the Office of Tax Consultants Husni \& Mulyadi Consulting. Relational quality variables are variables that most influence on loyalty to the Office of Tax Consultants Husni \& Mulyadi Consulting.
\end{abstract}

Keywords: Core quality, relational quality, perceived value, customer satisfaction, service switching, voice PENDAHULUAN

Salah satu cara membedakan sebuah perusahaan jasa dengan perusahaan jasa lainya adalah memberikan pelayanan dengan kualitas yang lebih tinggi dari pesaing secara konsisten. Ada dua faktor yang mempengaruhi kualitas pelayanan, yaitu antara yang diharapkan dan yang dirasakan (Tjiptono 2001). Jika pelayanan yang diterima sesuai dengan yang diharapkan, maka dipersepsikan baik dan memuaskan, jika melampaui harapan pelanggan dipersepsikan ideal, sebaliknya apabila yang diterima lebih

rendah daripada yang diharapkan akan dipersepsikan buruk (Kotler, 2009). Menurut Zeithaml, et. all., menjelaskan harapan pelanggan merupakan keyakinan pelanggan sebelum membeli produk yang dijadikan standar dalam menilai kinerja produk tersebut (Tjiptono, 2001).

Ekspektasi pelanggan dibentuk oleh pengalaman masa lalunya, pembicaraan dari mulut ke mulut dan promosi yang dilakukan perusahaan jasa. Pelanggan memilih penyedia jasa berdasarkan hal ini, dan setelah 
menerima jasa itu pelanggan membandingkan pelayanan yang dialami dengan pelayanan yang diharapkan. Menurut Tse dan Wilton, kepuasan atau ketidakpuasan pelanggan adalah respon pelanggan terhadap evaluasi ketidaksesuaian yang dirasakan antara harapan sebelumnya dan kinerja aktual produk yang dirasakan setelah pemakaian (Tjiptono, 2001).

Terjadinya persaingan yang ketat antar perusahaan jasa dalam mencari pelanggan menuntut setiap perusahaan yang ingin berkembang atau paling tidak bertahan hidup harus dapat memberikan kualitas yang baik agar dapat memiliki keunggulan dalam usaha memenangkan persaingan. Salah satu jenis jasa yang sedang marak adalah jasa konsultan pajak. Bisnis konsultan pajak memiliki tingkat kepastian yang tinggi artinya kelangsungan masa depan tidak hanya di tentukan oleh perusahaan tetapi juga kondisi ekonomi yang selalu berubah.

Jasa kantor konsultan pajak merupakan salah satu bisnis yang dinamis dengan persaingan yang ketat. Kondisi seperti ini perlu dihadapi dengan strategi pemasaran yang tepat. Salah satu cara yang dapat dilakukan dengan dengan membangun hubungan pelanggan. Dengan hubungan pelanggan ini perusahaan akan dapat menjual jasa dengan lebih mudah karena sudah dikenal oleh konsumen. Dengan hubungan pelanggan ini akan mengurangi keragu-raguan konsumen dalam memilih jasa konsultan pajak. Hubungan pelanggan yang berkualitas juga dapat menjamin kelangsungan usaha dalam jangka waktu yang lebih lama dan menjamin konsumen puas kepada perusahaan, dengan mengulang transaksi pada waktu lain.

Upaya memberikan kepuasan pada konsumen dapat berkontribusi pada sejumlah aspek penting salah satunya tercipta loyalitas pelanggan. Membentuk loyalitas salah satunya dengan memberikan kepuasan, pemberian manfaat atau value bagi konsumen dengan peningkatan kualitas, yaitu dengan memberikan keunggulan pada barang atau jasa yang dijual. Keunggulan suatu jasa tergantung pada keunikan serta kualitas yang diperlihatkan oleh jasa tersebut.

Pelanggan puas sebagai konsekuensinya mereka akan loyal, tetapi jika tidak puas mereka akan pindah ke jasa lain (service switching) dan melakukan keluhan (voice). Pelanggan yang tidak puas tentu saja akan merasa dirugikan karena mereka tidak mendapatkan perlakuan yang adil dari perusahaan dan mereka dapat melakukan tindakan-tindakan yang merugikan perusahaan, misalnya membicarakan kejelekan pelayanan kepada orang lain. Tetapi jika pelanggan puas maka akan merekomendasikan kepada orang lain untuk menggunakan jasa itu. Untuk menghindari hal tersebut di atas maka perusahaan harus meningkatkan kualitas pelayanan, baik itu kualitas pelayanan pada waktu pembelian maupun pasca pambelian yang akan berpengaruh terhadap loyalitas pelanggan.

Loyalitas konsumen dapat saja langsung dipengaruhi oleh kualiatas pelayanan, namun dari hasil penelitian yang dilakukan oleh Wong dan Sohal (2003), membuktikan bahwa untuk melahirkan loyalitas konsumen, maka 
pelayanan yang diberikan terlebih dahulu dirasakan oleh konsumen, sehingga akan muncul adanya kepuasan ataupun ketidakpuasan. Karena itulah kepuasan dapat menjadi variabel perantara, dengan kata lain kualitas pelayanan secara tidak langsung berpengaruh terhadap loyalitas melalui kepuasan konsumen. Kenyataan ini dapat menjadi bukti bahwa untuk melahirkan loyalitas, banyak variabel yang harus diperhatikan, sehingga kinerja perusahaan tidak sia-sia. Faktorfaktor yang sekiranya perlu menjadi perhatian antara lain kualitas pelayanan yang menyangkut inti pelayanan, pembinaan hubungan dengan pelanggan, nilai perusahaan dalam persepsi pelanggan, kepuasan konsumen, dan mengeleminir gangguan dalam ketidakjelasan menyangkut layanan perusahaan. Faktor-faktor tersebut seperti yang dikembangkan oleh Mc Dougall dan Levesque (2000), yaitu Core Quality, Relational Quality, Perceived Value, Customer Satisfaction, Service Switching dan Voice Terhadap Loyality.

\section{METODE PENELITIAN}

Metode analisis data yang digunakan peneliti dalam penelitian ini adalah Uji Validitas, Uji Realibilitas, Uji Asumsi Klasik, Analisis Regresi Linier Berganda (Multiple Regresion Analysis), Uji t (parsial) dan Uji F(simultan).

Pada penelitian ini digunakan SPSS (Statistical Product Service Solution). Cara kerja SPSS dapat diterangkan sebagai berikut pada

Gambar 3.1

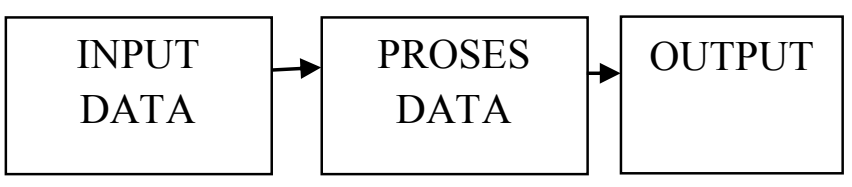

Penjelasan :

Data berupa angka (numeric) atau tipe data yang lain misalnya teks, dimasukkan setelah desain variabel (variable view) dibuat pada posisi data view dan kemudian dilakukan analisis atau pemrosesan data. Output berupa angka, tabel dan grafik. Interpretasi dilakukan sesuai kasus dan masalah yang dihadapi.

\section{HASIL DAN PEMBAHASAN}

Dalam penelitian ini peneliti menggunakan alat analisis regresi linier berganda untuk mengetahui pengaruh variabel independent terhadap variabel dependent, analisis ini digunakan untuk mengukur besarnya pengaruh antara variabel (X) independent yaitu core quality, relational quality, perceived value, customer satisfaction, service switching dan voice dengan variabel (Y) dependent yaitu loyality pada Kantor Konsultan Pajak Husni \& Mulyadi Consulting dengan rumus sebagai berikut :

$$
\begin{gathered}
\mathrm{Y}=\mathrm{a}+\mathrm{b}_{1} \mathrm{x}_{1}+\mathrm{b}_{2} \mathrm{x}_{2}+\mathrm{b}_{3} \mathrm{x}_{3}+\mathrm{b}_{4} \mathrm{X}_{4}+ \\
\mathrm{b}_{5} \mathrm{x}_{5}+\mathrm{b}_{6} \mathrm{x}_{6}
\end{gathered}
$$

Berdasarkan hasil analisis dengan menggunakan alat bantu SPSS, maka diperoleh Tabel 4.1 Hasil Regresi Linier Berganda

Tabel 4.1 Hasil Regresi Linier Berganda 


\begin{tabular}{|c|c|c|c|c|c|}
\hline \multicolumn{6}{|c|}{ Coefficients $^{\mathrm{a}}$} \\
\hline \multirow[t]{2}{*}{ Model } & \multicolumn{2}{|c|}{$\begin{array}{l}\text { Unstandardize } \\
\text { d Coefficients }\end{array}$} & \multirow{2}{*}{$\begin{array}{c}\text { Standardiz } \\
\text { ed } \\
\text { Coefficien } \\
\text { ts } \\
\text { Beta }\end{array}$} & \multirow[t]{2}{*}{ z } & \multirow[t]{2}{*}{ Sig. it } \\
\hline & B & $\begin{array}{l}\text { Std. } \\
\text { Error }\end{array}$ & & & \\
\hline (Constant) & 3,925 & 1,879 & & 2,089 &, 043 \\
\hline Core_quality_total &,- 023 & ,006 &,- 388 & $-3,740$ & ,001 \\
\hline Relational_quality_total & ,475 & ,097 &, 503 & 4,872 &, 000 \\
\hline Perceived_total &,- 014 & ,007 &,- 208 & $-2,049$ & ,047 \\
\hline Customer_ss_total & ,378 & ,097 & ,418 & 3,882 & ,000 \\
\hline Switching_total &,- 076 & ,057 &,- 143 & $-1,331$ & ,190 \\
\hline Voice total & ,103 & ,103 & , 103 & ,997 &, 324 \\
\hline
\end{tabular}

Sumber :Hasil penelitian, 2016 Data diolah

Hasil persamaan regresi linier bergandanya, yaitu :

$$
\begin{aligned}
Y= & 3,925-0,023 \quad X_{1}+0,475 X_{2^{-}} \\
& 0,014 X_{3}+0,378 X_{4}-0,076 \quad X_{5} \\
& +0,103 X_{6}
\end{aligned}
$$

Arti dari persamaan regresi linier berganda di atas yaitu sebagai berikut : $\mathrm{a}=3,925 \quad$ artinya konstanta tanpa adanya core quality, relational quality, perceived value, customer satisfaction, service switching dan voice maka loyality pada Kantor Konsultan Pajak Husni \& Mulyadi Consulting sebesar 3,925.

$\mathrm{b}_{1}=-0,023$ Jika aspek core quality naik satu satuan dan variabel lain tetap maka loyality pada Kantor Konsultan Pajak Husni \& Mulyadi Consulting akan turun sebesar 0,023 .

$\mathrm{b}_{2}=0,475$ Jika aspek relational quality, naik satu satuan dan variabel lain tetap maka loyality pada Kantor Konsultan Pajak Husni \& Mulyadi Consulting akan naik sebesar 0,475. $\mathrm{b}_{3}=-0,014 \mathrm{~J} \mathrm{ika}$ aspek perceived value naik satu satuan dan variabel lain tetap maka loyality pada Kantor Konsultan Pajak Husni \& Mulyadi
Consulting akan turun sebesar 0,014 .

$\mathrm{b}_{4}=0,378 \quad$ Jika aspek customer satisfaction naik satu satuan dan variabel lain tetap maka loyality pada Kantor Konsultan Pajak Husni \& Mulyadi Consulting akan naik sebesar 0, 378 .

$\mathrm{b}_{5}=-0,076$ Jika aspek service switching naik satu satuan dan variabel lain tetap maka loyality pada Kantor Konsultan Pajak Husni \& Mulyadi Consulting akan turun sebesar -0,079.

$\mathrm{b}_{6}=0,103$ Jika aspek voice naik satu satuan dan variabel lain tetap maka loyality pada Kantor Konsultan Pajak Husni \& Mulyadi Consulting akan naik sebesar 0 , 103.

\section{Uji Hipotesis}

Dengan bantuan program SPSS maka hasil uji t dapat dilihat pada Tabel 4.2 Hasil Uji t (Parsial).

Tabel 4.2 Hasil Uji t (Parsial)

Sumber : Hasil Penelitian, 2016 Data diolah Nilai thitung akan dibandingkan dengan nilai tabel pada tingkat kepercayaan $95 \%$ $(\alpha=0,05)$, maka diperoleh :

a) Pengaruh parsial dari variabel core quality $\left(\mathrm{X}_{1}\right)$ diperoleh dengan nilai

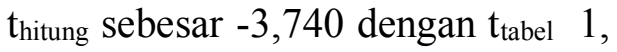
680 demikian $t_{\text {hitung }}>t_{\text {tabel}}$, yaitu 3,740 > 1, 680 maka Ho ditolak yang berarti bahwa variabel core quality $\left(\mathrm{X}_{1}\right)$ berpengaruh significant secara parsial loyality pada Kantor Konsultan Pajak Husni \& Mulyadi Consulting (Y).

b) Pengaruh parsial dari relational quality $\left(\mathrm{X}_{2}\right)$ diperoleh dengan nilai 
$t_{\text {hitung }}$ sebesar 4,872 dengan $t_{\text {tabel }} 1$, 680 demikian $t_{\text {hitung }}>t_{\text {tabel}}$, yaitu 4,872 > 1, 680 maka Ho ditolak yang berarti bahwa variabel relational quality $\left(\mathrm{X}_{2}\right)$ berpengaruh significant secara parsial terhadap loyality pada Kantor Konsultan Pajak Husni \& Mulyadi Consulting (Y).

c) Pengaruh parsial dari variabel perceived value $\left(\mathrm{X}_{3}\right)$, diperoleh dengan nilai $t_{\text {hitung }}$ sebesar $-2,049$ dengan $t_{\text {tabel }} 1,680$ demikian $t_{\text {hitung }}$ $>t_{\text {tabel}}$, yaitu $-2,049>1,680$ maka Ho ditolak yang berarti bahwa

\begin{tabular}{|c|c|c|c|c|c|}
\hline \multicolumn{6}{|c|}{ ANOVA $^{\mathrm{a}}$} \\
\hline Model & $\begin{array}{l}\text { Sum of } \\
\text { Squares }\end{array}$ & Df & Mean Square & $\mathrm{F}$ & Sig. \\
\hline Regression & 105,312 & 6 & 17,552 & 10,038 &, $000^{\mathrm{b}}$ \\
\hline Residual & 75,188 & 43 & 1,749 & & \\
\hline Total & 180,500 & 49 & & & \\
\hline
\end{tabular}
berpengaruh significant secara parsial terhadap loyality pada Kantor Konsultan Pajak Husni \& Mulyadi Consulting (Y).

d) Pengaruh parsial dari variabel customer satisfaction $\left(\mathrm{X}_{4}\right)$ diperoleh dengan nilai $t_{\text {hitung sebesar } 3,882}$ dengan $t_{\text {tabel }} 1,680$ demikian $t_{\text {hitung }}$ $>t_{\text {tabel}}$, yaitu 3,882 > 1, 680 maka Ho ditolak yang berarti bahwa variabel customer satisfaction $\left(\mathrm{X}_{4}\right)$ berpengaruh significant secara parsial terhadap loyality pada Kantor Konsultan Pajak Husni \& Mulyadi Consulting (Y).

e) Pengaruh parsial dari variabel service switching $\left(\mathrm{X}_{5}\right)$ diperoleh dengan nilai $t_{\text {hitung }}$ sebesar $-1,331$ dengan $t_{\text {tabel }} 1,680$ demikian $t_{\text {hitung }}$ $<\mathrm{t}_{\text {tabel, }}$ yaitu $-1,331<1,680$ maka Ho diterima yang berarti bahwa variabel service switching $\left(\mathrm{X}_{5}\right)$ tidak berpengaruh significant secara parsial terhadap loyality pada Kantor Konsultan Pajak Husni \& Mulyadi Consulting (Y).

f) Pengaruh parsial dari variabel voice $\left(\mathrm{X}_{6}\right)$ diperoleh dengan nilai $\mathrm{t}_{\text {hitung }}$ sebesar 0,997dengan tabel 1,680 demikian $t_{\text {hitung }}<t_{\text {tabel, }}$ yaitu $0,997<$ 1, 680 maka Ho diterima yang berarti bahwa variabel voice $\left(\mathrm{X}_{6}\right)$ tidak berpengaruh significant secara parsial terhadap loyality pada Kantor Konsultan Pajak Husni \& Mulyadi Consulting (Y).

\section{Uji F (Simultan)}

Hasil Uji F dapat dapat dilihat pada Tabel 4.3 berikut :

Tabel 4.3 Hasil Uji F (simultan)

Sumber : Hasil Penelitian, 2016 Data diolah Dari tabel 4.3 diperoleh nilai $F_{\text {hitung }}$ sebesar 10.038 dengan signifikansi 0,000 .

a. Dengan demikian $F_{\text {hitung }}>F_{\text {tabel }}$, yaitu $10.038>2,31$. maka Ho ditolak dan Ha diterima yang berarti bahwa core quality $\left(\mathrm{X}_{1}\right)$, relational quality $\left(\mathrm{X}_{2}\right)$, perceived value $\left(\mathrm{X}_{3}\right)$, customer satisfaction $\left(\mathrm{X}_{4}\right)$, service switching $\left(\mathrm{X}_{5}\right)$ dan voice $\left(\mathrm{X}_{6}\right)$ berpengaruh significant secara simultan terhadap loyality pada Kantor Konsultan Pajak Husni \& Mulyadi Consulting.

b. Hal ini dapat dilihat dari nilai uji signifikansi pada uji $\mathrm{F}$ sebesar 0,000 yang lebih kecil dari pada $\alpha=0,05$, maka significant menunjukan bahwa secara simultan core quality $\left(\mathrm{X}_{1}\right)$, relational quality $\left(\mathrm{X}_{2}\right)$, perceived value $\left(\mathrm{X}_{3}\right)$, customer satisfaction $\left(\mathrm{X}_{4}\right)$, service switching $\left(\mathrm{X}_{5}\right)$ dan voice $\left(\mathrm{X}_{6}\right)$ berpengaruh terhadap loyality 
pada Kantor Konsultan Pajak Husni

\& Mulyadi Consulting.

Untuk mengetahui variabel bebas yang paling berpengaruh terhadap variabel terikat dengan melihat nilai kuadrat korelasi tertinggi pada tabel 4.4 di bawah ini.

Tabel 4.4 Kontribusi variabel bebas terhadap varibel Loyality pada Kantor Konsultan Pajak Husni \& Mulyadi Consulting.

\begin{tabular}{lcrr}
\hline $\begin{array}{l}\text { Variabel } \\
\text { Bebas }\end{array}$ & $\begin{array}{l}\text { Koefesien } \\
\text { Korelasi }\end{array}$ & $\mathrm{r}^{2}$ & \multicolumn{2}{c}{$\begin{array}{l}\text { Kontrib } \\
\text { usi }\end{array}$} \\
\hline $\begin{array}{l}\text { core quality } \\
\text { relational } \\
\text { quality } \\
\text { perceived }\end{array}$ & 0,300 & 0,09 & $9 \%$ \\
$\begin{array}{l}\text { value } \\
\text { customer }\end{array}$ & 0,574 & 0,33 & $33 \%$ \\
$\begin{array}{l}\text { satisfaction } \\
\text { service } \\
\text { switching }\end{array}$ & $-0,329$ & 0,11 & $11 \%$ \\
voice & 0,275 & 0,08 & $8 \%$ \\
\hline
\end{tabular}

Berdasarkan tabel 4.4 di atas di ketahui bahwa diantara variabel core quality, relational quality, perceived value, customer satisfaction, service switching dan voice yang paling berpengaruh terhadap loyality pada Kantor Konsultan Pajak Husni \& Mulyadi Consulting yaitu variabel relational quality.

\section{KESIMPULAN}

Berdasarkan hasil penelitian dan pembahasan yang telah diuraikan pada bab sebelumnya, maka dapat disimpulkan sebagai berikut :

1. Variabel core quality, relational quality, variabel perceived value, dan customer satisfaction berpengaruh significant secara parsial loyality pada Kantor Konsultan Pajak Husni \& Mulyadi Consulting. Sedangkan service switching dan voice tidak berpengaruh significant secara parsial terhadap Customer loyality pada Kantor Konsultan Pajak Husni $\&$ Mulyadi Consulting.

2. Variabel Core quality, relational quality, perceived value, customer satisfaction, service switching, dan voice berpengaruh significant secara simultan terhadap loyality pada Kantor Konsultan Pajak Husni \& Mulyadi Consulting.

3. Variabel yang paling berpengaruh diantara Core quality, relational quality, perceived value, customer satisfaction, service switching, dan voice terhadap loyality pada Kantor Konsultan Pajak Husni \& Mulyadi Consulting yaitu relational quality.

\section{DAFTAR PUSTAKA}

Al Rasyid, Harun, 2004. Teknik Penarikan Sampel dan Penyusunan Skala. Bandung : Program Pasca Sarjana Universitas Padjadjaran.

Anderson,E.W, Fornell,C and Lehmann, D.R., 2004, "Customer Satisfaction, Market Share and Probability: findings from Sweden". Journal of marketing, Vol 58, July,pp 53-66.

Andreassen dan Lindestad, 2006. Customer loyalty and complex services The impact of corporate image on quality, customer satisfaction and loyalty for customers with varying degrees of service expertise. International Journal Of Service Industry Management. Vol 9 No. I 1998. p 7 -23 . 
Ball et all. 2006. Service personalization and loyalty. Journal of Services Marketing Volume 20 Number 6 2006 pp. 391-403.

Fornell,C. Johnson, M.D., Anderson, E.W.,Cha, J and Bryant B.E., 2006, "The American Customer Satisfaction Index:Nature, Purpose and Findings". Journal of Marketing, Vol.60, October, pp.718.

Grace and O'Cass, 2001, “Attributions of Service Switching: a study of customers' and providers' perceptions of child care service delivery" Journal of Service Marketing Vol. 15 pp 300-321.

Ghozali, Imam. 2011. Aplikasi Analisis Multivariat dengan Program IBN SPSS 19. Jakarta : Badan Penerbit Universitas Diponegoro

Jay Kandampully dan Dwi Suhartanto. 2000. Customer loyalty in the hotel industry: the role of customer satisfaction and image. International Journal of Contemporary Hospitality Management Volume 12 Number 6 2000 pp. 346-351.

Kotler, P., 2009, Manajemen Pemasaran: Edisi Milenium, Alih Bahasa Benjamin Molan, Prenhalindo, Jakarta.

McDougall,G.H and Levesque,T., 2000, "Customer satisfaction with service: putting perceived value into the equation". Journal of services marketing, Vol. 14,No.5, pp 392410.

Parasuraman, A., Zeithaml,V.A. and Berry,L.L., 2005, "A Conceptual Model of Service Quality and Its
Implications for Future Research". Journal of The Marketing, Vol.49, Fall, pp 41-50.

Petrick,J.F., 2002 "Development of a Multi-Dimensional Scale For Measuring The Perceived Value of a Service". Journal of Leisure Research, Vol.34, No.2. pp.119134.

Petterson and Spreng, 2003, "Modelling the relationship between perceived value, satisfaction and repurchase intention in a business-to-business, service context: an empirical examination". International Jounal of Service Industry Management; Bradford.

Suliyanto, 2011. Ekonometrika Terapan. Teori \& Aplikasi Penerbit Andy Offset Yogyakarta

$\begin{array}{ll}\text { Pemasaran. } & \text { 2001. Strategi } \\ \text { Yogyakarta. } & \end{array}$

Tjiptono, 2001, "Loyalitas Pelanggan" Jurnal Bisnis Indonesia, Vol 4 No.3 pp 73-88.

Umar, Husein, 2000, Riset Pemasaran dan Perilaku Konsumen, Jakarta : Gramedia Pustaka Utama dan Jakarta Bussiness Research Center.

Wong dan Sohal, 2003. Service quality and customer loyalty perspectives on two levels of retail relationships. Journal of Services Marketing Volume 17 Number 5 2003 pp. 495-513. 